\title{
Tejiendo certezas en la incertidumbre: anuncios en establecimientos comerciales
}

\section{Weaving certainties in uncertainty: advertisements in commercial establishments}

\author{
Enriqueta Leonor Rivera Cañizales* \\ Universidad Anáhuac México \\ Av. Universidad Anáhuac núm. 46, \\ Col. Lomas Anáhuac, C. P. 52786, Huixquilucan, \\ Estado de México, México \\ Universidad Anáhuac Querétaro \\ Calle Circuito Universidades I, kilómetro 7, \\ Fracción 2, El Marqués, C.P.76246, Querétaro, México \\ Editor: Rogelio del Prado Flores \\ Fecha de recepción: 30 de junio de 2020 \\ Fecha de aceptación: 21 de julio de 2020
}

\author{
enriqueta.rivera17@anahuac.mx \\ https://orcid.org/0000-0001-7619-9173
}

https://doi.org/10.36105/stx.2020edespcovid-19.07 


\section{RESUMEN}

El análisis del discurso de anuncios en establecimientos comerciales durante la pandemia, desde una despedida hasta la instrucción de toma de sana distancia, ofrecen evidencias de la construcción de un sentido humano, de interacción mediada por el lenguaje como representaciones cognitivas conforme la realidad concreta lo demanda.

Los anuncios son analizados como un escenario práctico de intercambio de bienes que presentan elementos de carácter lingüístico, semiótico, cognitivo, antropológico cultural y de toma de decisiones profesionales, bajo la perspectiva epistemológica Constructivista Radical y otras aportaciones teórico-metodológicas y técnico-profesionales, sus contribuciones a la comunidad, sentido de identidad y respuestas en estos tiempos del covid-19, son objetivados con la herramienta Mirada Profesional con Razonamiento Inclusivo, identificando constructos comunicativos que dan esperanza y certezas en tiempos de incertidumbre.

Palabras clave: discurso, razonamiento inclusivo, actores y sentido.

\section{ABSTRACT}

Advertisements made by hand or print are analyzed as a complex scenario for the exchange of services or products, because they exhibit elements of a linguistic, semiotic, cognitive, cultural anthropological nature and professional decision-making, under the radical constructivist epistemological perspective, and other aspects theoretical-methodological and technical-professional. The contributions of advertising to the community are the sense of identity and coexistence before COVID-19; This research analyzes the ads with the Inclusive Reasoning tool, identifying communicative constructions that give hope and certainty in times of uncertainty.

Keywords: discourse, inclusive reasoning, actors and meaning. 


\section{INTRODUCCIÓN}

L os tiempos vividos son apocalípticos, dirían los abuelitos del siglo antepasado; sin embargo, aun en escenarios como este, las acciones en comunicación tienden redes de empatía, fortalecimiento de identidades y subsistencia de personas, por ejemplo, quienes coinciden en tiendas comerciales para conseguir productos y servicios. Son espacios de convivencia multiformes que subsisten en plena pandemia gracias a las experiencias compartidas, la comunicación sensible y solidaria desde, para y con el cliente.

Es decir, las interacciones cotidianas construyen y tejen redes que dan sentido y razones de vida, porque la mediación simbólica a través del lenguaje, que es un espejo esencial de certidumbre de la propia existencia y la del "otro"; por eso se tejen certezas en época de incertidumbre, en la pandemia y aun en establecimientos comerciales; de ahí el título del artículo.

El paradigma epistemológico de la investigación es el Constructivismo Radical que reconoce la mediación simbólica del lenguaje desde un punto de vista cognitivo; además son incluidas aportaciones de la Hermenéutica, Antropología Cultural y otras áreas; porque sumar varias perspectivas y dimensiones de un suceso a investigación, se construye conocimiento más cercano a la realidad concreta, esto es, se construye una imagen objetiva de un recorte en tiempo, espacio, actores y escenarios determinados.

El objetivo es identificar elementos cognitivos-lingüísticos, epistemo-metodológicos, semióticos-antropológicos y profesional, inmersos en los letreros de locales comerciales dirigidos a consumidores del nivel socioeconómico C+, C-, D y E, que contribuyen al desarrollo de comunidades, identidades y respuesta ante un presente y futuro pandémico. Es decir, es un análisis formal de anuncios utilizados por comercios durante la pandemia, que contribuyen en la construcción de certeza y esperanza aun en los peores momentos, como espejos de un "ya pasará".

Los hallazgos principales son que los procesos comunicativos detonados a partir de los letreros de los comercios en época de pandemia potencian la construcción de sentido de vida, comunidad, identidad, con la posibilidad de esperanza en un presente mejor, a partir de anuncios que rebasan la utilidad práctica de una herramienta de mercadotecnia. 


\section{MARCO TEÓRICO Y CONTEXTUAL}

En estos meses, mucha es la oferta de estudios, reflexiones y análisis del impacto del covid-19 en la humanidad, desde la filosofía hasta el e-commerce con la variable significativa del aumento en usuarios a nivel global. Sin embargo, solo el $44 \%$ de los mexicanos tienen computadora y 56.4\% tiene acceso a internet (Simetría, 2020), por ello, es indispensable analizar escenarios comunicativos alternativos donde convergen dimensiones de la realidad física y digital, que apoyan la reestructuración de la "nueva normalidad" (Mesa Editorial, 2020).

\section{Comportamientos y preocupaciones como condicionantes}

El marco para comprender las implicaciones de anuncios comerciales en la interacción cotidiana que construye certezas son las etapas que transitan las personas y asumen la pandemia como parte de su vida y que representan distintos comportamientos que pueden dividirse en etapas (IPsos Public Affairs, 2020), con base en el estudio de IPS os Global Advisor, aplicando 28,00 0 encuestas online a adultos entre el 16 y 19 de abril de 2020 .

FIGURA 1. ETAPAS DE COMPORTAMIENTO DE PERSONAS

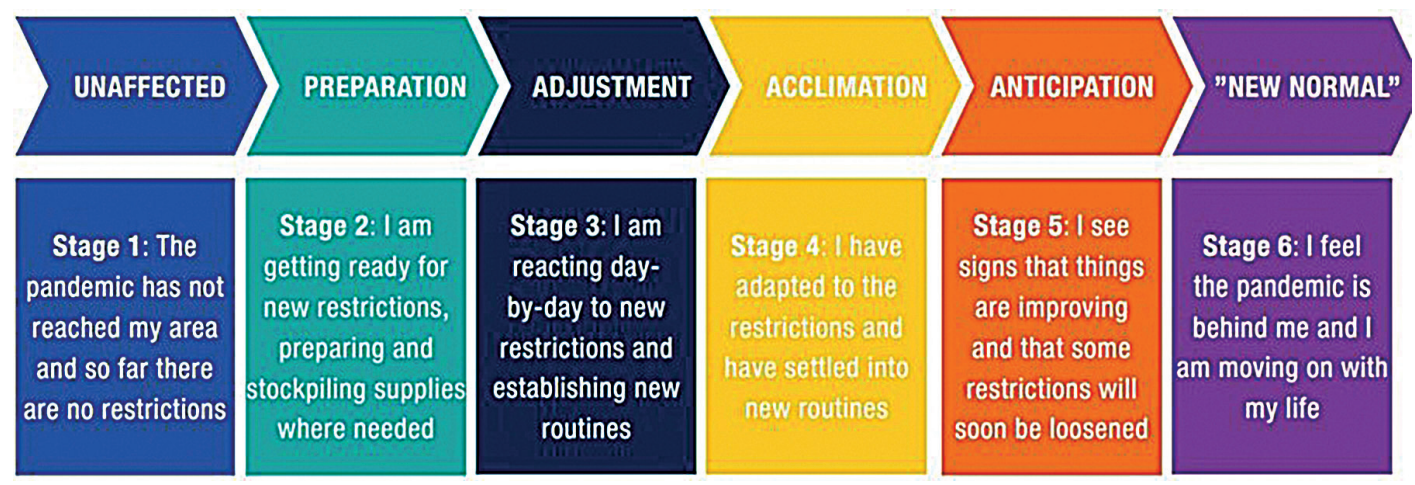

Fuente: I IPSOS Public AfFAIRS, 2020.

Las etapas condicionan los procesos vividos en el intercambio de bienes y servicios, transformando el comportamiento del consumidor al reducir el contacto cercano, el trabajo en casa, el pago con tarjeta, entre otros, que se describirse 
como "Low-Touch Economy" (Ansons, 2020), es decir, sus preocupaciones y toma de decisiones de consumidores continúan cambiando.

FIGURA 2. PREOCUPACIONES EN MÉXICO

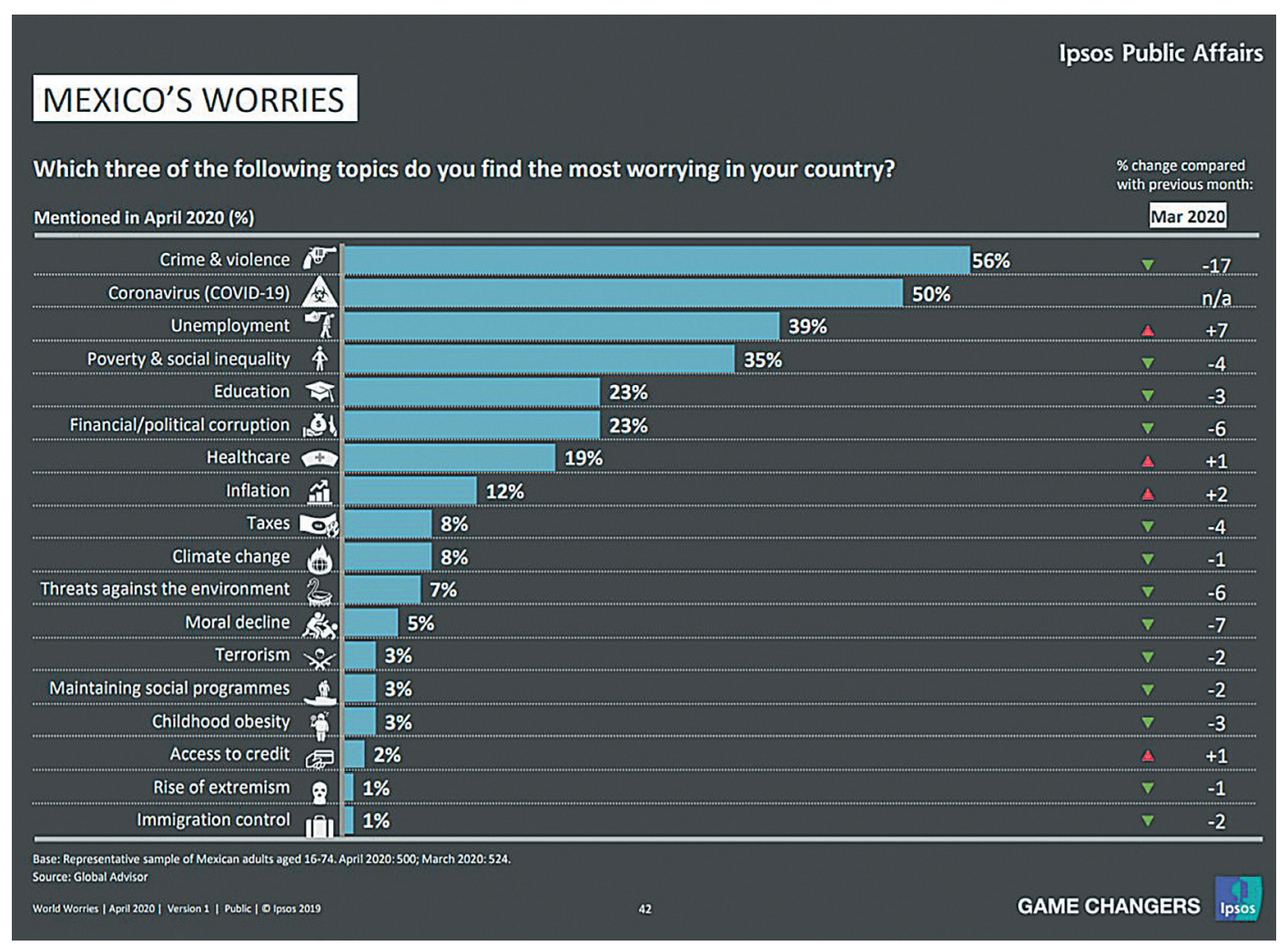

Fuente: IPSOS PUbLIC AfFAIRS, 2020.

En el caso de México, las preocupaciones están concentradas en primer lugar en la violencia y en segundo, el coronavirus, y en este contexto las personas acuden a abastecerse de alimentos, productos de limpieza, ropa y otros a locales comerciales. A los factores macro mencionados, debe sumarse el cambio de comportamientos de clientes y usuarios, por ello las aportaciones de Heriberto López (Instituto de Investigaciones Sociales, 2018) son pertinentes al tipificar los niveles socioeconómicos con categorías de narrativas sociales. 


\section{Locales comerciales y cultura mexicana}

Los establecimientos comerciales son puntos neurálgicos de la economía al ser más de un millón de tiendas de abarrotes y de las cuales dependen más de 3 millones de personas (CONCANACO, 2020). Es tal su importancia, que fue lanzado el programa "Tienda Segura" para apoyarles para sobrevivir la pandemia y continuar ofreciendo sus servicios.

Cabe señalar que las tiendas de abarrotes también son parte de la cultura mexicana porque contribuyen a la construcción de identidades y distribución de riqueza a lo largo de los siglos. Por ejemplo, la memoria colectiva convierte en canciones la relevancia de la tienda para los grupos sociales; así lo demuestra la canción "En la esquina de mi barrio" escrita por Chava Flores en 1957: "En la esquina de mi barrio hay una tienda que se llama 'La ilusión del Porvenir', junto de ella está la fonda de Rosenda que en domingos le echa al mole ajonjolí... Y la esquina me consuela en mi amargura con su risa, su bullicio y su esplendor" (Flores, 2020).

Y en tiempos de pandemia, el politólogo destacado José Woldenberg escribe con preocupación, tristeza y análisis político-económico sobre la situación que atraviesan las tiendas (Woldenberg, 2020), incluyendo en su artículo la tienda "La ilusión del Porvenir": “...Esa esquina llena de vida, plaza fundamental para el encuentro y el comercio, hoy se apaga poco a poco. Y con ello la economía y las expectativas de millones".

\section{Localización e imagen comercial}

En los establecimientos comerciales los clientes adaptan su cuerpo a esos escenarios, por ejemplo, cuando se hace fila o el hablar bajo, conversando sobre la familia, la comida, los hijos, entre otros temas y donde los vendedores tienen que atraer la atención de sus clientes (De Certeau, 1999), como "no lugares" (Augé, 1992) al ser lugares reconstruidos por las mismas personas trascendiendo su propósito práctico.

Por ejemplo, las tiendas ubicadas en la colonia Condesa de la Ciudad de México están inmersas en un espacio que conforme el tiempo y prácticas de quienes viven y transitan, lo han convertido en una mezcla particular, entre lo moderno, tradicional, exclusivo, excluido, nacional y cosmopolita (Hurtado, D. \& Aguirre, G., 2017).

En las colonias, los comercios son parte de la vida cotidiana donde se conversa sobre la familia o el clima, facilitando la construcción de identidades, sentido de vida e intercambio de bienes; más aun en estos tiempos de incertidumbre, tristeza 
profunda, muerte y con la esperanza puesta en el día siguiente. En estos espacios es que los anuncios físicos toman particular relevancia en tiempos de la COVD-19.

\section{Cartulinas fluorescentes e interacción}

Los letreros elaborados en cartulinas fluorescentes son utilizados en establecimientos comerciales para dirigirse a sus clientes y todo aquel que transite cerca del negocio, a veces con una comunicación formal y otras más con el particular sentido del humor de muchos mexicanos.

IMAGEN 1. LETRERO CON ADVERTENCIA

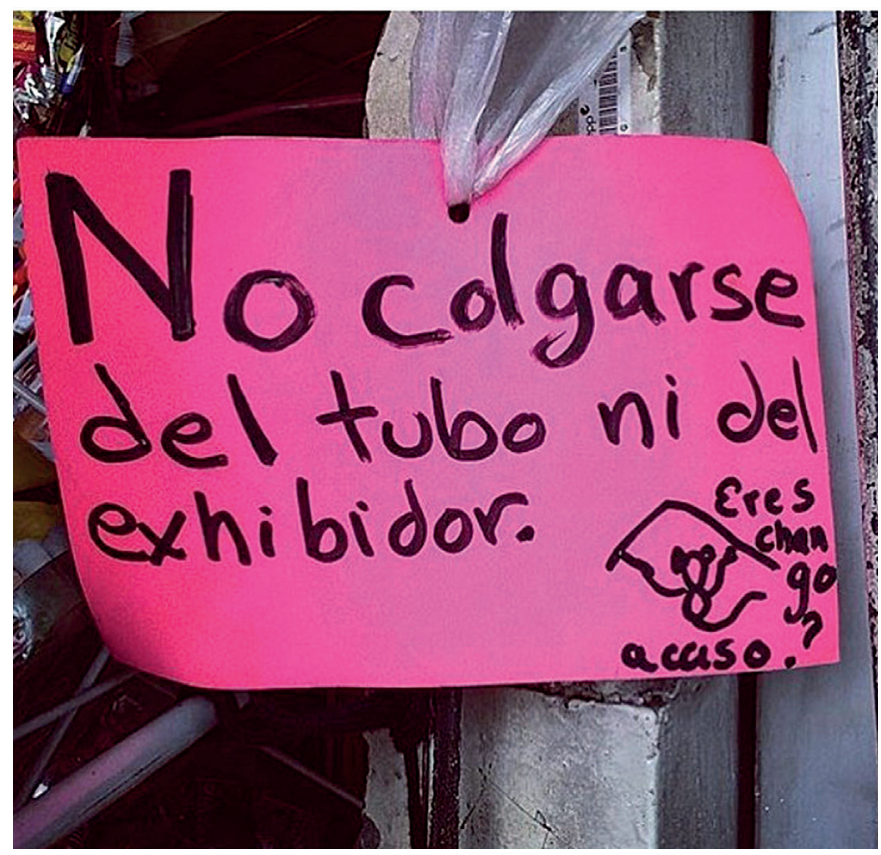

CRÉDITO: CARTULINAS FLOURESCENTES, 2020.

Las cartulinas fluorescentes tienen el propósito de llamar la atención del consumidor desde décadas atrás, por lo que forman parte de la cultura mexicana y conocimiento cotidiano; es tal su impacto que es posible encontrar en redes sociodigitales como Instagram, Cartulinas Fluorescentes (Cartulinas Flourescentes, 2020) que cuenta con más de 28 mil seguidores. Por supuesto, también se utilizan anuncios formales sobre tela ahulada con impresión digital. 


\section{Epistemología lingüístico-cognitiva}

Tras describir un tránsito de lo macro a lo micro, es posible argumentar que frente a este objeto de estudio complejo: las cartulinas fluorescentes y anuncios formales es necesario comprender, utilizar y aprehenderlo desde la perspectiva epistemológica Constructivista Radical (Glasersfeld, 2007), que tiene como una de sus premisas: "Lo que normalmente llamamos realidad es la realidad de las estructuras perceptivas y conceptuales relativamente duraderas que logramos establecer, usar y mantener en el flujo de nuestra experiencia real" (Glasersfeld, 2007, 36). Además de la perspectiva lingüística de la filosofía, donde la interacción es con y en la realidad detonando procesos de construcción cognitiva individual y social en escenarios comunicativos, porque "el ser que puede ser comprendido es lenguaje" (Nieto, 1997, 239).

Es la complejidad mediada por representaciones cognitivas de la realidad, convergen las herramientas cognitivas y fisiológicas, de ahí que las aportaciones de la neurociencia sean pertinentes porque para que "...algo sea cognoscitivamente comprendido...la persona se ha tomado el tiempo suficiente para reconstruir elementos cognoscibles en su más completa expresión con el mínimo de recursos necesarios" (Monroy-Fonseca, 2019, 172) y algunas de sus aplicaciones a entornos de compra, refieren a que un "bien que se materializa de forma cognoscitiva en la mente del consumidor, pero se ejecuta de forma activa en la tienda y con el dinero y el bien físico" (Monroy-Fonseca, 2019, 69).

La mirada cognitiva-lingüística-epistemológica como perspectiva de análisis del discurso también contempla una ecología de los medios (Postman, 1991) entendiendo por ecología "... el estudio de los ambientes, es decir, la observación sobre su estructura, contenido e impacto sobre las personas" (Velázquez, 2018, 586), si bien el suceso de análisis son los anuncios de comercios, los clientes y transeúntes, éstos también pueden ser usuarios de la internet, aun aquellos que no tienen computadora, es parte del sociolecto desarrollado en el día a día.

Aquí una representación gráfica de la complejidad y riqueza que implica la interacción desde la postura epistemológica y metodológica de esta investigación.

En el análisis de los anuncios de establecimientos comerciales coinciden: el contexto vivido de la pandemia, la historia del comercio con sus clientes, interacciones significativas y una base de acuerdos en escenarios comunicativos formales o no, que más allá de la prestación de un servicio, contribuyen en la construcción de certezas a pesar de tristezas profundas en personas, grupos sociales y especie humana. 
FIGURA 3. REPRESENTACIÓN DE PARADIGMA DE ESTA INVESTIGACIÓN

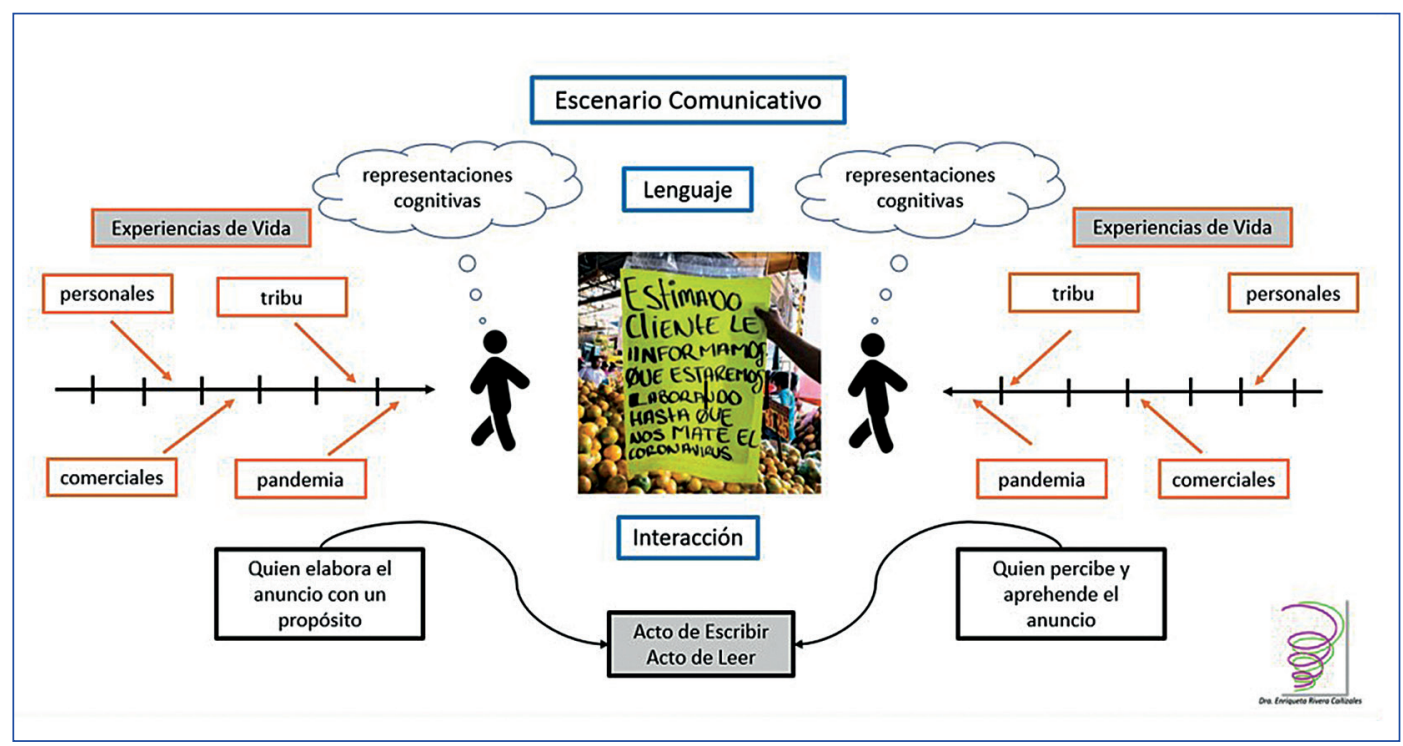

FUENTE: ELABORACIÓN PROPIA.

\section{Pandemia y posconsumismo}

En momentos de crisis en dimensiones el proceso de comprensión es crucial, como lo enuncia Edgar Morin en una entrevista: "Me parece importante prepararse para entender las interconexiones: cómo una crisis sanitaria puede provocar una crisis económica que, a su vez, produce una crisis social y, por último, existencial" (Ordine, 2020).

Por supuesto, es en el actuar cotidiano de comunidades físicas y digitales, que los andamios son construidos para avanzar y sanar, ya que: "La solución para cada problema estratégico es la confianza, y aquellos que recuerdan a la tribu el coste de fallar; que es la extinción, no añaden nada a la sabiduría colectiva más que el miedo paralizante de la muerte" (Scruton, 2010, p. 187). Los anuncios de establecimientos comerciales son parte de estos biófilos andamios.

En este marco de preocupaciones y acciones, una reciente publicación de Phillip Kotler "The consumer in the Age of Coronavirus" (2020) desarrolla la categoría de posconsumismo porque: "Más personas buscarán lograr un mejor equilibrio entre trabajo, familia y ocio. Muchos pasarán de una adicción al materialismo a sentir otros caminos hacia una buena vida". Entreteje los propósitos comerciales con la calidad de vida de consumidores, inclinando en esta ocasión 
la balanza hacia los beneficios de los clientes como seres humanos. Su propuesta es una perspectiva adecuada, ya que la realidad no corresponde a un objeto de estudio dividido en parcelas de exclusividad en la construcción de conocimiento verdadero.

\section{METODOLOGÍA}

La investigación es un estudio exploratorio utilizando la estrategia de análisis del discurso como suceso: anuncios en establecimientos comerciales en tiempos de pandemia; fue diseñada conforme se ha consolidado y renovado la base cognitivo-lingüística- epistemológica-metodológica aprehendida a partir de la investigación de tesis doctoral (Rivera, 2010), donde se aplicó a situaciones reales, la metodología de análisis proposicional (Campos, 2005) que trabaja sobre conocimiento cotidiano, conocimiento formal y conocimiento científico como representaciones cognitivas de la realidad.

Conforme los aprendizajes y vivencias profesionales, la estrategia de análisis del discurso se transformó en una herramienta denominada Mirada profesional con razonamiento inclusivo (Rivera, 2019), de elaboración propia, representado a continuación.

\section{FIGURA 4. MIRADA PROFESIONAL CON RAZONAMIENTO INCLUSIVO}

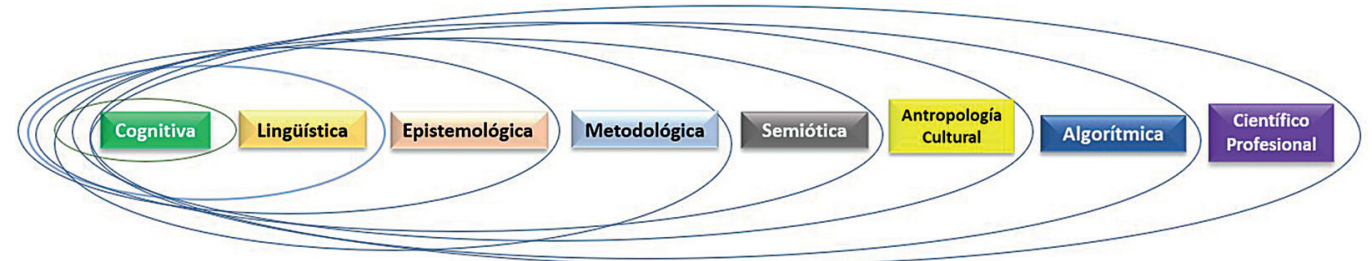

FUENTE: RIVERA, 2019.

Para facilitar la comprensión del razonamiento inclusivo, cabe recordar lo que es y no es la suma en la aritmética. 
FIGURA 5. SUMA. ADAPTACIÓN.

COGNOSCITIVISMO EPISTEMOLÓGICO

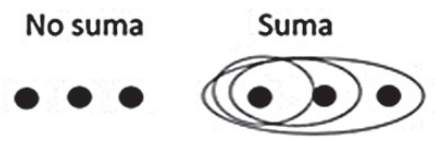

Fuente: Piaget, 1975.

Es decir, si cada elemento de análisis es aislado se tiene como resultado una visión subjetiva de la realidad en tanto ésta, entrelaza dimensiones y niveles de realidad de acuerdo con el recorte en tiempo y espacio, así como de los actores y sistemas presentes. Entonces, analizar describiendo cada elemento solo es enlistarlos fuera de contexto.

El criterio de análisis de la herramienta está compuesto por las siguientes dimensiones:

a) Cognitiva: Representaciones que incluyen acciones, imágenes, sonidos, letras, palabras integradas en los procesos cognitivos del cerebro, objetivados en lenguaje y que orientan el actuar humano.

b) LINGÜÍSTICA: Representaciones de letras y palabras que construyen imágenes de la realidad a partir de textos e intencionalidades asignadas.

c) EPISTEMológicA: Construcción de conceptos de verdad ya sea desde el conocimiento cotidiano, conocimiento formal y conocimiento profesional.

d) METodológicA: Lógica formal y procedimental, como secuencia no lineal de acciones y representaciones para la construcción de conocimiento.

e) SEMiótiCA: Representaciones gráfica, visual, auditiva, entre otras, plenas de significados asignados por actores comunicativos y sistemas.

f) ANTRopológico CUltural: Pautas de comportamiento y rituales propios de grupos en determinados contextos cargados de significados, así como representaciones sociales. 
g) ALGORÍTMICA: Instrucciones en secuencia que registran acciones de usuarios en redes sociodigitales, por ejemplo.

h) Científico profesional: Concepciones, decisiones y técnicas propias del ámbito de la mercadotecnia, publicidad y de negocios, entre otros.

Las representaciones sociales son resultado de representaciones cognitivas que responden a situaciones determinadas y se modifican conforme lo requiere la realidad; el grupo de acciones que se repiten son un hábito, un hábito que se repite es una costumbre y ésta a su vez puede transformarse en una visión de mundo y sistemas.

Las dimensiones metodológica y algorítmica no son pertinentes a esta investigación. El suceso analizado son anuncios de establecimientos comerciales en tiempo de la covid-19 en la zona metropolitana, considerando su texto, diseño y actores comunicativos en situaciones de interacción cotidiana.

Los anuncios fueron seleccionados dentro de la temporada de la pandemia y son textos utilizados por locales comerciales e información dirigida a clientes y usuarios, en entornos físicos, aunque por supuesto también el comercio electrónico del marketing digital impacta en la construcción de interpretaciones y reacciones de consumidores.

Las tablas de análisis contienen las ideas claves de tres anuncios, con imágenes correspondientes, así como la fecha y a quienes está dirigido. Como se indicó arriba, la forma de leer el análisis debe ser inclusiva, es decir una columna dentro de otra, porque al aislar la información se descompone el escenario comunicativo dando como resultado una visión distorsionada de la realidad.

Tampoco ha de revisarse de izquierda a derecha, sino del elemento que le resulta más atractivo dependiendo de su propósito de comprensión, análisis e investigación. En negritas una selección de elementos claves para el ejercicio de análisis, lo cual no implica que los otros sean descartados, porque todos son parte de una lectura en diferentes niveles de realidad y de los actores dentro de un mismo suceso. 


\section{RESULTADOS}

Primero, partir de que, con base a los anuncios seleccionados para su análisis, puede afirmarse que se ubican entre la etapa 3 de ser reactivos y etapa 4 de adaptación a nuevas rutinas.

Al estar restringida la salida de personas y la amenaza de contagiarse, llevó a los negocios a utilizar herramientas alternativas de comunicación con sus clientes; en el caso del metro, funcionó parcialmente debido a lo sustantivo de su servicio para la Ciudad de México y zona metropolitana. Y a pesar de las recomendaciones de las autoridades, algunas organizaciones no protegieron a sus trabajadores como deberían.

\section{Trabajadores del Metro se quejan}

El primer anuncio (Cartulinas Flourescentes, 2020) analizado es elaborado por trabajadores de las taquillas del metro a inicios de la pandemia, el 23 de marzo de este año. A continuación, la fotografía del anuncio y el análisis correspondiente.

IMAGEN 2. TRABAJADORES DEL METRO SE QUEJAN

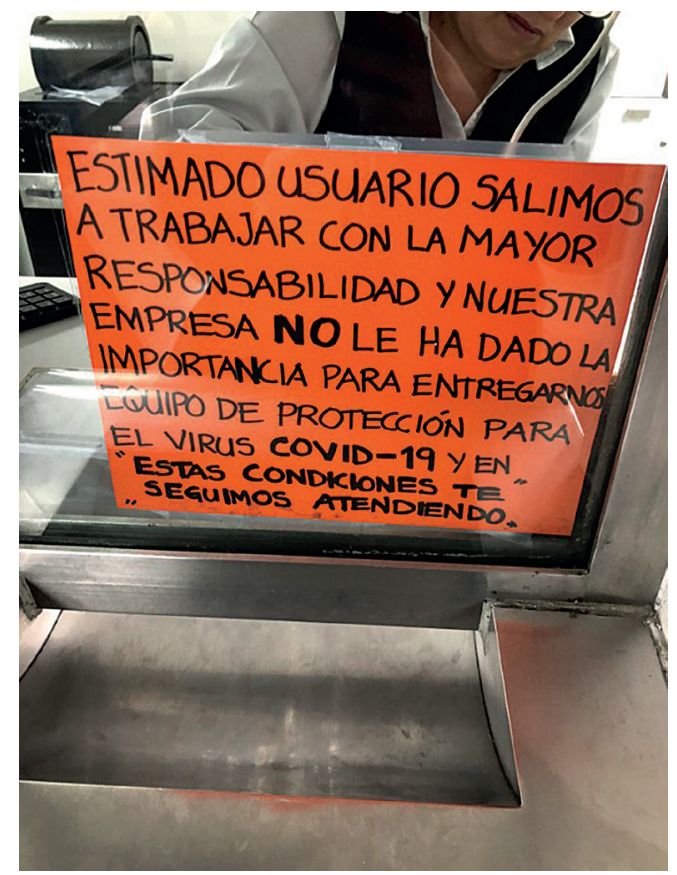


TABLA 1. TRABAJADORES DEL METRO SE QUEJAN

\begin{tabular}{|c|c|c|c|c|c|}
\hline COGNITIVO & LINGUÍSTICO & EPISTEMOLÓGICO & SEMIÓTICO & $\begin{array}{l}\text { ANTROPOLÓGICO } \\
\text { CULTURAL }\end{array}$ & $\begin{array}{l}\text { CIENTÍFICO } \\
\text { PROFESIONAL }\end{array}$ \\
\hline $\begin{array}{l}\text { Representación de la } \\
\text { realidad: } \\
\text { Metro. } \\
\text { Microescenario de } \\
\text { compra. } \\
\text { Interacción humana } \\
\text { mediada por un } \\
\text { cristal. } \\
\text { Procedimiento de } \\
\text { compra. } \\
\text { Vendedor. } \\
\text { Comprador. } \\
\text { Dinero. } \\
\text { Tiempo de } \\
\text { adquisición de } \\
\text { boleto o recarga de } \\
\text { tarjeta. } \\
\text { Espacio fijo y usuario } \\
\text { en tránsito. }\end{array}$ & $\begin{array}{l}\text { Salimos de un } \\
\text { espacio seguro a estar } \\
\text { expuestos. } \\
\text { Responsabilidad: } \\
\text { cumplimiento en el } \\
\text { trabajo. } \\
\text { Mayor en el contexto } \\
\text { de riesgo. } \\
\text { Empresa: organización } \\
\text { en donde está inserto. } \\
\text { No importancia: } \\
\text { carencia de } \\
\text { cumplimiento. } \\
\text { Protección: amenaza } \\
\text { de muerte. } \\
\text { Condiciones: entre lo } \\
\text { ideal o real. } \\
\text { Seguimos. a pesar } \\
\text { de... } \\
\text { Atendiendo: a ustedes } \\
\text { que dan razón de } \\
\text { nosotros. }\end{array}$ & $\begin{array}{l}\text { Verdad construida } \\
\text { desde la vivencia } \\
\text { del trabajador. } \\
\text { Conocimiento de la } \\
\text { realidad presente } \\
\text { por parte del } \\
\text { usuario. } \\
\text { Realidad amenaza } \\
\text { de muerte. } \\
\text { Codependencia: } \\
\text { trabajo, servicio y } \\
\text { cumplimiento de } \\
\text { objetivo. } \\
\text { Apropiación y } \\
\text { transformación } \\
\text { de espacio de } \\
\text { interacción. }\end{array}$ & $\begin{array}{l}\text { Letra formal en } \\
\text { mayúscula, en } \\
\text { negrita lo más } \\
\text { relevante. } \\
\text { En ventanilla } \\
\text { microespacio } \\
\text { de interacción } \\
\text { que ante la } \\
\text { prisa de compra } \\
\text { del boleto, no } \\
\text { necesariamente } \\
\text { es leído. } \\
\text { Letrero media } \\
\text { interacción con } \\
\text { usuario. } \\
\text { Procedimiento } \\
\text { de compra y } \\
\text { dimensión } \\
\text { humana de } \\
\text { sobrevivencia. }\end{array}$ & $\begin{array}{l}\text { Vínculo afectivo. } \\
\text { Compromiso } \\
\text { profesional. } \\
\text { Solidaridad entre } \\
\text { trabajadory } \\
\text { usuario. } \\
\text { Aun a costa de su } \\
\text { salud/vida ofrece } \\
\text { el servicio. } \\
\text { Tres tribus: } \\
\text { trabajador, } \\
\text { usuario, empresa. } \\
\text { Agente dañino. } \\
\text { Firmes } \\
\text { cumpliendo aun } \\
\text { en situación de } \\
\text { riesgo de vida. }\end{array}$ & $\begin{array}{l}\text { Compromiso laboral } \\
\text { cumplido versus } \\
\text { empresa carente de } \\
\text { responsabilidad. } \\
\text { Opinión pública } \\
\text { en escenario } \\
\text { específico de } \\
\text { interacción } \\
\text { en proceso de } \\
\text { adquisición de un } \\
\text { servicio. }\end{array}$ \\
\hline
\end{tabular}

FUENTE: ELABORACIÓN PROPIA.

El ser humano al nacer tiene la capacidad de interactuar con la realidad comunicarse, sin embargo, debe desarrollar las herramientas en un situaciones sociales y condiciones propias de la realidad. Entonces, las interacciones cotidianas potencian la construcción de representaciones cognitivas que delinean imágenes de la realidad, incluyendo actores, escenarios, procedimientos y decisiones. La interacción entre vendedor y comprador tiene representaciones cognitivas de lo que es y hace un vendedor y comprador definido formalmente pero que adquieren significados en tanto el escenario de interacción y propósitos. Las representaciones son herramientas de convivencia y consecución de objetivos flexibles conforme la realidad lo demande. 
Es así que los capitalinos se conducen diariamente con las representaciones cognitivas de vendedor y comprador que, en este caso, son insertadas en un escenario de incertidumbre, enfermedad y muerte diferencia a la experiencia de vida cotidiana pero no para la especie humana.

El vendedor de boletos traspasa el procedimiento de venta apelando a la solidaridad del comprador de boletos, cambiando su rol de usuario que debe utilizar el transporte para trasladarse para sus actividades sustantivas.

Tanto comprador como vendedor necesitan trabajar por lo que convergen dos necesidades de los actores comunicativos que participan de un procedimiento instituido por la organización: venta y compra de boletos; no se conocen como personas, pero sí bajo la representación de trabajadores que necesitan proveer de las condiciones mínimas de sobrevivencia en un sistema de mercado.

Dicha situación requiere modificar el concepto de responsabilidad de la empresa porque las condiciones son extremas y nuevas. La organización tendría que ser flexible y reducir la curva de aprendizaje sobre procedimientos instituidos para responder con apego a norma y ética sobre acciones vinculadas con la integridad física y psicológica de su capital humano.

Bajo esta representación formal de respuesta organizacional que dan marco a la interacción entre vendedor y comprador; la empresa no cumple con su responsabilidad, y es ahí donde los trabajadores como actores comunicativos de la Ciudad de México -que tiene historia sobre acciones de la sociedad civil y solidaridad en situaciones extremas- apelan a la opinión pública de la cual forma parte el usuario de forma consciente o no.

Puede afirmarse que, el vendedor y comprador desconocen el concepto de opinión pública como tampoco analizado las acciones de muchas personas en el temblor del 2017; sin embargo, la construcción de conocimiento cotidiano como resultado de la interacción mediada simbólicamente, les permite tener representaciones cognitivas que son herramientas al desenvolverse en la realidad concreta. Por ello, es posible apelar a la empatía y solidaridad del comprador y aprovechar un espacio de coincidencia física para hacerse escuchar y quizás tener una respuesta de la empresa a través de la visibilidad pública en su ámbito de trabajo. Fueron tomadas medidas sanitarias con usuarios y trabajadores, aunque también tuvo que intervenir su sindicato, medios de comunicación y redes sociodigitales.

El texto legible es hecho a mano, con el tamaño suficiente para ser leído; cabe señalar que en una ciudad donde el anonimato es una de sus características, 
el acto de coincidir en el mismo lugar y a la misma hora, permite interactuar, conocerse un poco, solo lo indispensable para ser visto, escuchado y tener como espejo al otro.

El anuncio es contundente, no se autorregula y contiene información de la situación que viven los trabajadores, y aun cuando el comprador puede pasar de prisa por su boleto, en los tiempos vividos es indispensable denunciar y aprovechar materiales y espacios porque también los otros padecen situaciones similares.

\section{Mantener la distancia}

Teniendo presente el análisis anterior, es posible comprender mejor la complejidad y riqueza de estos anuncios, porque los procesos cognitivos son inclusivos y lo aprendido en un escenario puede ser aplicado a otro parecido. El segundo anuncio refiere de forma explícita a la sana distancia (Cartulinas Flourescentes, 2020).

IMAGEN 3. MANTENER LA DISTANCIA

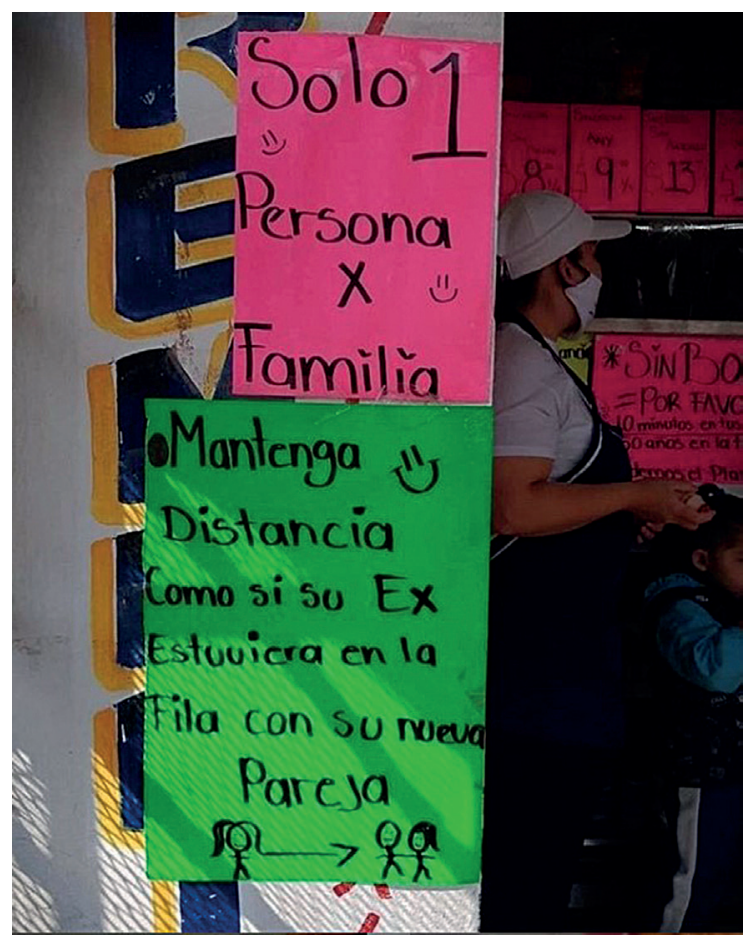

CRÉDITO: CARTULINAS FLOURESCENTES, 2020. 
TABLA 2. MANTENER LA DISTANCIA

\begin{tabular}{|c|c|c|c|c|c|}
\hline COGNITIVO & LINGUÍSTICO & EPISTEMOLÓGICO & SEMIÓTICO & $\begin{array}{l}\text { ANTROPOLÓGICO } \\
\text { CULTURAL }\end{array}$ & $\begin{array}{l}\text { CIENTÍFICO } \\
\text { PROFESIONAL }\end{array}$ \\
\hline $\begin{array}{l}\text { Representación } \\
\text { de la realidad: } \\
\text { familia más de } \\
\text { uno. } \\
\text { Distancia: } \\
\text { espacio entre. } \\
\text { Como si: } \\
\text { condición no } \\
\text { presente en el } \\
\text { momento. } \\
\text { Su ex: su de } \\
\text { suyo. } \\
\text { Nueva pareja: no } \\
\text { es usted. }\end{array}$ & $\begin{array}{l}\text { Instrucciones en } \\
\text { imperativo sobre } \\
\text { comportamiento en } \\
\text { el establecimiento } \\
\text { comercial. } \\
\text { Mantenga: debido a } \\
\text { que la fila se mueve } \\
\text { al ser atendidos y } \\
\text { eso lleva a reducir } \\
\text { la distancia entre } \\
\text { clientes. } \\
\text { Para la comprensión: } \\
\text { asegura dirigirse desde } \\
\text { una situación común, } \\
\text { sabida por todos: } \\
\text { pareja-rompimiento- } \\
\text { expareja-nueva pareja. }\end{array}$ & $\begin{array}{l}\text { Supuesto de } \\
\text { pareja, desde } \\
\text { quien escribe. } \\
\text { Tiempo pasado y } \\
\text { presente. } \\
\text { Representación } \\
\text { de la toma de } \\
\text { distancia desde } \\
\text { el conocimiento } \\
\text { cotidiano del } \\
\text { "después" del } \\
\text { rompimiento de } \\
\text { pareja. } \\
\text { Aún se tienen } \\
\text { sentimientos } \\
\text { hacia esa } \\
\text { persona. } \\
\text { Espacio de } \\
\text { comercio: con } \\
\text { orden para el bien } \\
\text { común. }\end{array}$ & $\begin{array}{l}\text { Ubicación a la } \\
\text { entrada del negocio: } \\
\text { ruta del consumidor. } \\
\text { Representación } \\
\text { gráfica: sonrisas } \\
\text { como expresión de } \\
\text { alegría, gentileza en } \\
\text { comunicación con el } \\
\text { consumidor. } \\
\text { Distancia con flecha } \\
\text { y línea que marca } \\
\text { espacio. } \\
\text { Uno solo: menos } \\
\text { espacio ocupado, } \\
\text { proxemia. } \\
\text { Pareja (dos): } \\
\text { hombre (cabello } \\
\text { corto); mujer } \\
\text { (cabello largo). } \\
\text { Colores de cada } \\
\text { cartulina solo de } \\
\text { contraste. }\end{array}$ & $\begin{array}{l}\text { Familia: ante el hábito } \\
\text { de ir a comprar juntos } \\
\text { por circunstancias } \\
\text { diversas como: niños } \\
\text { salieron de la escuela. } \\
\text { Mantenga: por el hecho } \\
\text { de reunirse en sitio de } \\
\text { compra, conocidos o no } \\
\text { conocidos. } \\
\text { Compra en pareja: } \\
\text { ritual constante en sus } \\
\text { compradores o desde } \\
\text { la realidad de quien } \\
\text { escribe el letrero. } \\
\text { Fila: personas formadas } \\
\text { en línea en espera de } \\
\text { obtener un beneficio. } \\
\text { Nueva pareja de su } \\
\text { exnovio: ya que quien } \\
\text { toma distancia es una } \\
\text { mujer o bien exnovia } \\
\text { desde la diversidad. }\end{array}$ & $\begin{array}{l}\text { La empatía } \\
\text { no como } \\
\text { solidaridad sino } \\
\text { la capacidad de } \\
\text { ponerse en lugar } \\
\text { del otro para } \\
\text { argumentar, } \\
\text { inducir e } \\
\text { indicar un } \\
\text { comportamiento } \\
\text { determinado. } \\
\text { Instrucción } \\
\text { afable de } \\
\text { comportamiento } \\
\text { a seguir. }\end{array}$ \\
\hline
\end{tabular}

FUENTE: ELABORACIÓN PROPIA.

El contexto es un marco que modifica las acciones y sus significados dependiendo de los actores y propósitos. Un factor determinante en tiempos de pandemia son las indicaciones gubernamentales para la sobrevivencia y control de la COVID-19; es el gobierno una estructura instituida por la sociedad para su representación bajo muy diversas ideologías. Lo cierto es que en tiempos de incertidumbre se requiere tener certeza en las decisiones y acciones a seguir para la sobrevivencia, uno de estos apoyos es el gobierno, como también especialistas glocales. 
Las instrucciones gubernamentales son: uso de gel antibacterial, cubrebocas y la sana distancia que también son requisitos para la apertura de negocios comerciales, y este anuncio del pasado mes de junio invita a sus clientes de forma explícita a mantener la sana distancia.

La interacción en los espacios de servicios es fundamental, ya que de ella depende por mucho de la empatía entre vendedor y comprar o usuario del servicio, es una representación cognitiva que media el éxito o fracaso de un negocio, un ejemplo de ello es el engagement que entre otros elementos hace de la empatía una herramienta para detonar las acciones del consumidor alineado al ADN de la empresa para mantener una relación comercial duradera en un ganar-ganar.

En el texto convergen la norma de salud con la experiencia cotidiana de una relación de pareja. La representación cognitiva, resultado de interacciones a lo largo de los siglos y del día a día, es la cercanía física entre dos personas que comparten un sentimiento como el amor en sus múltiples acepciones. Es la representación de pareja parte del acervo social de conocimiento (Berger \& Luckmann, 1966), es una etiqueta lingüística que tiene muchos significados y continúa transformándose como toda representación simbólica de la realidad.

El concepto de distancia es también clave en la comprensión e interpretación del texto en su contexto (Nieto,1997), la proxemia media la interacción y muestra el tipo de relación entre las personas o bien la situación por la que están atravesando; por ello la etiqueta "sana distancia" en tanto procura la salud entre las personas, más no un escenario negativo en afectos.

En este contexto es que las personas del local comercial construyen empatía y comprensión sobre el comportamiento requerido para obtener el servicio; de ahí que el mensaje sea fácil y ágil de leer apoyándose en gráficos, sin que por ello vulnere a sus clientes, aun cuando la instrucción es imperativa. Cabe recordar que mucha de la publicidad que se consume es imperativa, aunque en el siglo XxI poco a poco se hace realidad un respeto al consumidor, sobre todo en entornos digitales.

El anuncio entrelaza el ciclo básico de una pareja: tener una pareja, rompimiento y vuelta a encontrarse, lo que genera sentimientos que pueden reflejarse con la decisión casi instintiva de tomar distancia como mecanismo de sobrevivencia, de análisis para decidir el mejor comportamiento o simplemente sorpresa; estas acciones se insertan en el escenario de compra de su negocio y son representaciones aprendidas en la interacción cotidiana y son coordenadas de actuación en sociedad. 
Los seres humanos son animales de rituales, de acciones cargadas de significados que rebasan un procedimiento para darle sentido con relación a la sobrevivencia de la especie. Los rituales son heredados y se transforman igual en circunstancias del día a día en los ambientes analógicos que en entornos digitales. El anuncio refiere a uno de los núcleos de la sociedad: la familia, aunque según puede ser una sola persona (INEGI, 2017). Por eso es interesante que el anuncio remita a la costumbre de sus clientes de llegar a comprar en familia, como ritual que también es observado en grandes supermercados; así que el acto de comprar está cargado de significados que rebasan el acto de compra.

En los tiempos actuales, la mercadotecnia insiste en la necesidad de ponerse en el lugar del otro, de mostrar empatía, de generar el engagement, aquí un ejemplo sencillo de la capacidad de producción del texto desde el conocimiento cotidiano; de ahí la relevancia del anuncio.

\section{Restaurante se depide}

IMAGEN 4. RESTAURANTE SE DESPIDE

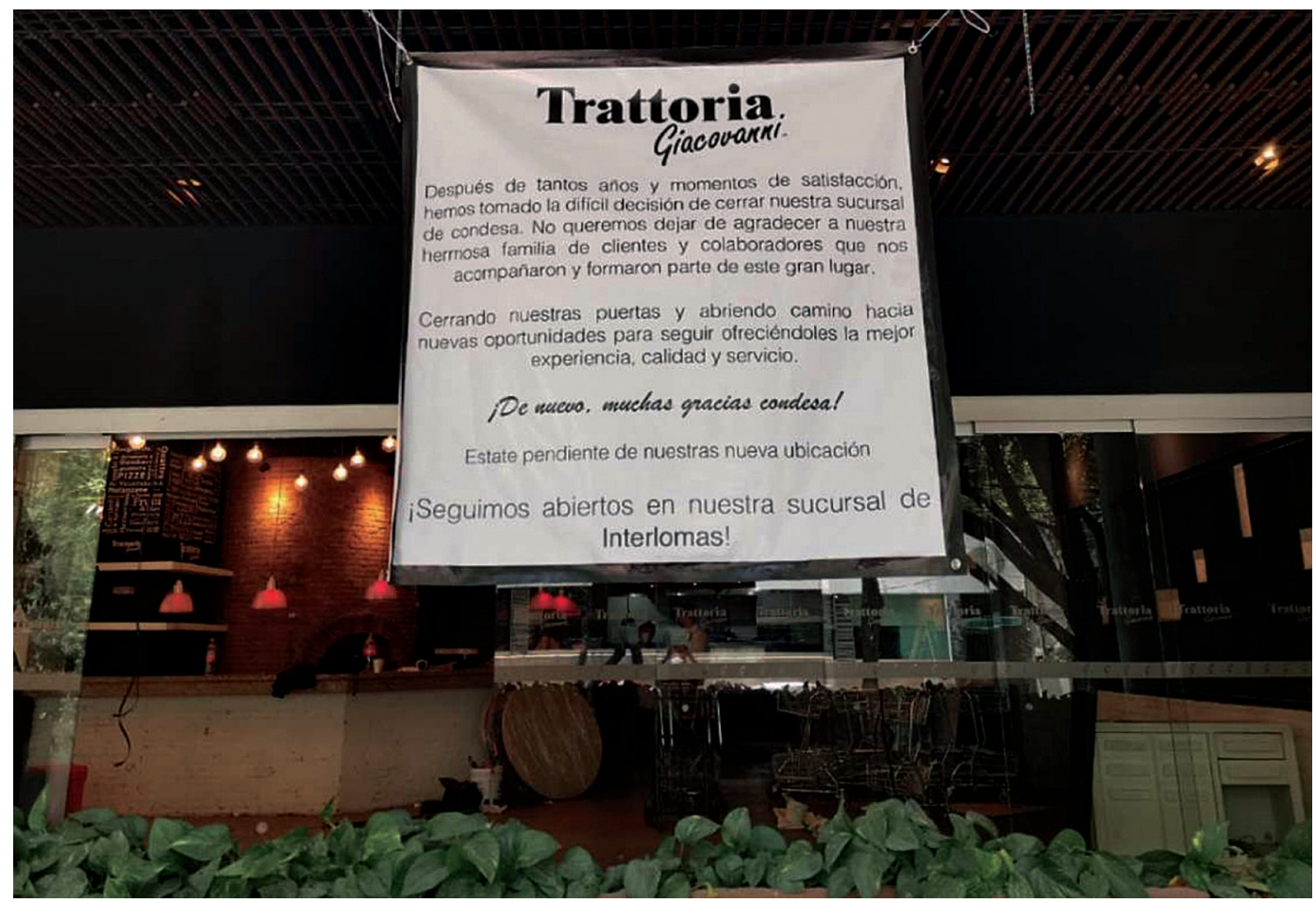

CRÉDITO: SD NOTICIAS, 2020. 
TABLA 3. RESTAURANTE SE DESPIDE

\begin{tabular}{|c|c|c|c|c|c|}
\hline COGNITIVO & LINGUÍSTICO & EPISTEMOLÓGICO & SEMIÓTICO & $\begin{array}{l}\text { ANTROPOLÓGICO } \\
\text { CULTURAL }\end{array}$ & $\begin{array}{c}\text { CIENTÍFICO } \\
\text { PROFESIONAL }\end{array}$ \\
\hline $\begin{array}{l}\text { Representación } \\
\text { de la realidad: } \\
\text { Trattoria: de } \\
\text { restaurante a } \\
\text { fonda. } \\
\text { Fonda: espacio } \\
\text { de cercanía entre } \\
\text { personas. } \\
\text { Tiempo lineal y } \\
\text { no lineal. } \\
\text { Acciones de } \\
\text { personas como } \\
\text { constructoras. }\end{array}$ & $\begin{array}{l}\text { Instrucciones en } \\
\text { imperativo sobre } \\
\text { comportamiento } \\
\text { en el } \\
\text { establecimiento } \\
\text { comercial. } \\
\text { Mantenga: debido a } \\
\text { que la fila se mueve } \\
\text { al ser atendidos y } \\
\text { eso lleva a reducir } \\
\text { la distancia entre } \\
\text { clientes. } \\
\text { Para la } \\
\text { comprensión: } \\
\text { asegura dirigirse } \\
\text { desde una situación } \\
\text { común, sabida } \\
\text { por todos: pareja- } \\
\text { rompimiento- } \\
\text { expareja-nueva } \\
\text { pareja. }\end{array}$ & $\begin{array}{l}\text { Supuesto de } \\
\text { pareja, desde quien } \\
\text { escribe. } \\
\text { Tiempo pasado y } \\
\text { presente. } \\
\text { Representación } \\
\text { de la toma de } \\
\text { distancia desde } \\
\text { el conocimiento } \\
\text { cotidiano del } \\
\text { "después" del } \\
\text { rompimiento de } \\
\text { pareja. } \\
\text { Aún se tienen } \\
\text { sentimientos hacia } \\
\text { esa persona. } \\
\text { Espacio de } \\
\text { comercio: con orden } \\
\text { para el bien común. }\end{array}$ & $\begin{array}{l}\text { A las afueras del } \\
\text { negocio, en la } \\
\text { ruta de andar del } \\
\text { cliente. } \\
\text { Destaca tipos de } \\
\text { letras: } \\
\text { - Nombre del } \\
\text { restaurante } \\
\text { - Descripción de la } \\
\text { situación } \\
\text { - Agradecimiento } \\
\text { - Estar pendiente } \\
\text { - En letra más } \\
\text { grande: sucursal } \\
\text { abierta } \\
\text { Colores sobrios } \\
\text { y sobre éste la } \\
\text { calidez del tiempo } \\
\text { compartido } \\
\text { y a seguir } \\
\text { coincidiendo. }\end{array}$ & $\begin{array}{l}\text { Espacio de convergencia } \\
\text { en determinado } \\
\text { tiempo, con propósitos } \\
\text { instrumentales y } \\
\text { emotivos. } \\
\text { Rituales de comercios: } \\
\text { satisfacción como } \\
\text { motivación a continuar. } \\
\text { Cierre de un ciclo, cargado } \\
\text { de significaciones } \\
\text { positivas en tanto } \\
\text { otras oportunidades o } \\
\text { terminación de una. } \\
\text { Trayecto compartido: } \\
\text { clientes y trabajadores. } \\
\text { Familia como una de las } \\
\text { tribus de la cual se forma } \\
\text { parte como incluyendo } \\
\text { colaboradores. } \\
\text { Condes, espacio } \\
\text { particularmente cargado } \\
\text { de significados. }\end{array}$ & $\begin{array}{l}\text { Se invita a seguir } \\
\text { coincidiendo en } \\
\text { otros lugares } \\
\text { para beneficio } \\
\text { del negocio y } \\
\text { clientes como } \\
\text { familia. } \\
\text { Engagement } \\
\text { construido a lo } \\
\text { largo del tiempo, } \\
\text { coincidencias, } \\
\text { afectos y servicio.. }\end{array}$ \\
\hline
\end{tabular}

FUENTE: ELABORACIÓN PROPIA.

La traducción de trattoria es fonda; en el contexto cultural mexicano fonda tiene varios significados dependiendo de grupos sociales y sus juicios previos, en tanto que una fonda puede ser ese lugar frecuente, amigable y cálido en el acto social sustantivo de comer y coincidir, pero también significa un lugar de baja calidad para otros consumidores. En este caso, la combinación de nombre, idioma extranjero y la historia compartida con clientes y colaboradores, transforma de facto al restaurante en un espacio que se frecuenta, amigable, cálido y con rica comida; por eso la relevancia de analizar los anuncios como evidencia de trayectorias sociales mediadas por el lenguaje e inmersos en sistemas en donde las acciones humanas determinan o condicionan. 
En las tribus, la comunicación es fundamental para mantener y alimentar los tejidos sociales que dan sentido a la vida y a ello se agregan propósitos comerciales como parte de los recursos para la sobrevivencia económica del negocio. Es un anuncio cimentado en experiencias compartidas donde el tiempo no es marcado por el reloj ni el calendario de forma lineal, sino por los sucesos valiosos compartidos en el espacio del negocio comercial; el tiempo, las acciones y objetos como las personas les son asignados múltiples significados.

A los significados asignados al texto y sus lectores debe agregarse un elemento de análisis desde la antropología cultural porque en la Condesa convergen el siglo XVIII y en siglo XxI, donde familias, transeúntes, turistas, políticos, intelectuales y muchos otros, construyeron un espacio que muchos seguidores de las redes sociodigitales y marketing digital quisieran replicar de forma inmediata.

¡No láser!

IMAGEN 5. iNO LÁSER!

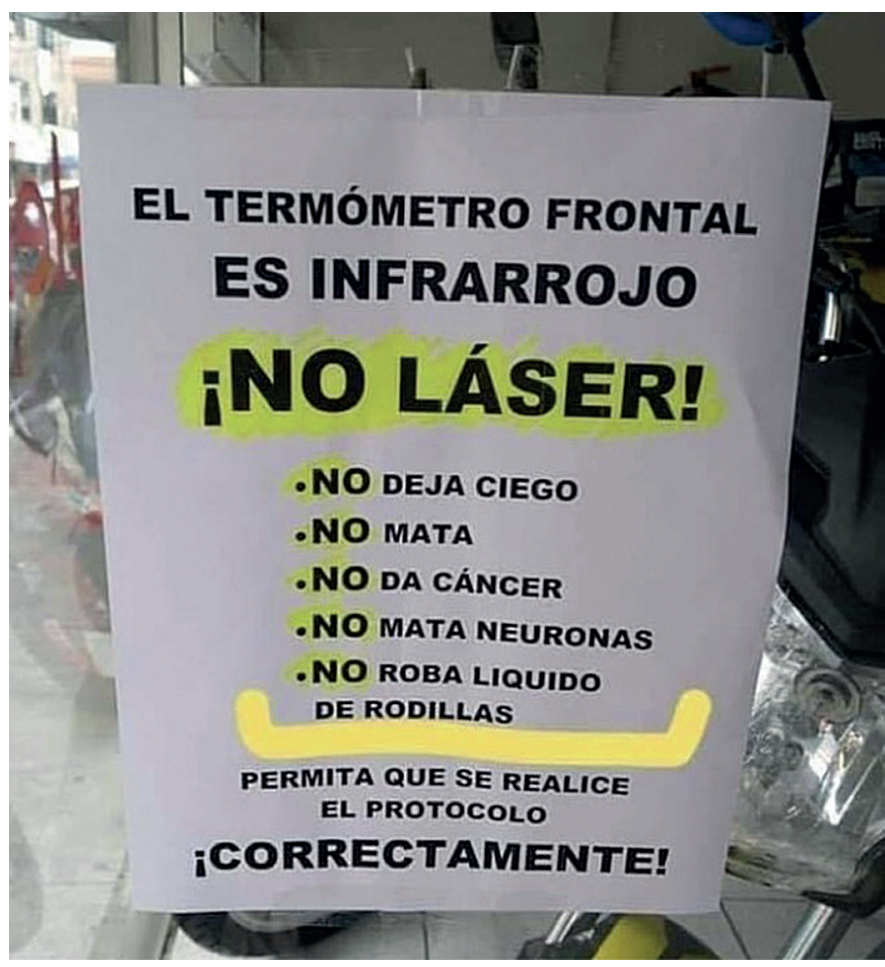

CRÉDITO:

BACQUERIE, 2020. 
TABLA 4. iNO LÁSER!

\begin{tabular}{|c|c|c|c|c|c|}
\hline COGNITIVO & LINGUÍSTICO & EPISTEMOLÓGICO & SEMIÓTICO & $\begin{array}{l}\text { ANTROPOLÓGICO } \\
\text { CULTURAL }\end{array}$ & $\begin{array}{l}\text { CIENTÍFICO } \\
\text { PROFESIONAL }\end{array}$ \\
\hline $\begin{array}{l}\text { Frontal:parte } \\
\text { sustantiva del } \\
\text { cuerpo. } \\
\text { Representaciones } \\
\text { de daño, } \\
\text { enfermedad y } \\
\text { muerte vinculadas } \\
\text { al color rojo. } \\
\text { Láser: } \\
\text { representación } \\
\text { alimentada } \\
\text { por discurso de } \\
\text { décadas atrás } \\
\text { como dañino. } \\
\text { Partes del cuerpo } \\
\text { que pueden } \\
\text { enfermarse. }\end{array}$ & $\begin{array}{l}\text { Conjunto de } \\
\text { palabras que } \\
\text { enuncian } \\
\text { enfermedades. } \\
\text { Infrarrojo como } \\
\text { sinónimo de dañino. } \\
\text { Rodillas:quizás } \\
\text { población adulta } \\
\text { mayor. } \\
\text { Cáncer: enfermedad } \\
\text { más frecuente casi } \\
\text { sinónimo de muerte. } \\
\text { Afirmaciones } \\
\text { en negativo sin } \\
\text { evidencias de } \\
\text { verdad. } \\
\text { Permita: invitación a } \\
\text { colaborar. }\end{array}$ & $\begin{array}{l}\text { Correctamente } \\
\text { como criterio } \\
\text { de verdad } \\
\text { procedimental. } \\
\text { Protocolo: } \\
\text { procedimiento. } \\
\text { Láser: herramienta } \\
\text { de ficción. } \\
\text { Consecuencias del } \\
\text { uso del láser. } \\
\text { Argumento } \\
\text { científico } \\
\text { traducido } \\
\text { a lenguaje } \\
\text { cotidiano. }\end{array}$ & $\begin{array}{l}\text { Subrayados } \\
\text { amarillos para } \\
\text { enfatizar el mensaje. } \\
\text { Color rojo como } \\
\text { amenaza. } \\
\text { Acto de apuntar con } \\
\text { un instrumento en } \\
\text { contexto violento. } \\
\text { Anuncio a la } \\
\text { entrada, ubicación } \\
\text { adecuada para } \\
\text { aplicación de } \\
\text { protocolo. } \\
\text { Lo que se anuncia } \\
\text { no necesariamente } \\
\text { se procesa con } \\
\text { significados } \\
\text { esperados. }\end{array}$ & $\begin{array}{l}\text { Rechazo al } \\
\text { protocolo. } \\
\text { Interacción } \\
\text { mediada por } \\
\text { instrumento } \\
\text { desconocido. } \\
\text { Ausencia de } \\
\text { experiencias con } \\
\text { herramientas } \\
\text { tecnológicas como } \\
\text { el termómetro } \\
\text { frontal. } \\
\text { Ciertos niveles } \\
\text { socioeconómicos } \\
\text { con pocas o nulas } \\
\text { experiencias } \\
\text { previas con láser } \\
\text { infrarrojo. }\end{array}$ & $\begin{array}{l}\text { Acción como } \\
\text { apego a las } \\
\text { recomendaciones } \\
\text { médicas, } \\
\text { gubernamentales } \\
\text { y de comercio. } \\
\text { Argumentación } \\
\text { con propósitos } \\
\text { comerciales y salud } \\
\text { de personas. }\end{array}$ \\
\hline
\end{tabular}

FUENTE: ELABORACIÓN PROPIA.

Dos diferencias sustantivas con relación a los anuncios revisados hasta este momento: primero, el argumento científico que presenta plasmado en lenguaje cotidiano, por estar escrito de forma afirmativa y contundente con el propósito de convencer al cliente de realizar el procedimiento para que los comercios puedan trabajar. Convencer, no con evidencias de laboratorio porque el escenario es otro.

Llama la atención los efectos dañinos que tiene el termómetro frontal infrarrojo desde el conocimiento cotidiano de grupos sociales, por eso es valiosa la información que presenta sobre enfermedades y consecuencias enlistadas, porque resultan de la experiencia de utilizar la herramienta con clientes y sus expresiones ante dicha situación. La lista es ilustrativa de experiencias con el láser, porque el acervo social de conocimiento lo etiquetó como dañino.

Cabe señalar que no se utiliza la palabra ignorante ya que el conocimiento cotidiano responde a las experiencias de vida, objetivos, prioridades y entornos; si 
fuese así, las personas que viven en las ciudades serían "ignorantes" al desconocer como cosechar el maíz.

Las supuestas enfermedades contrastan con la redacción del anuncio porque sus términos formales "termómetro frontal infrarrojo", corresponde a un diseño formal en impresora. Sin embargo, teje puentes entre las realidades y prejuicios de los grupos sociales de sus clientes, porque la lectura es un acto que involucra actores comunicativos en un espacio intersubjetivo (Habermas, 1999).

Antes de pasar al último anuncio, es importante tener presente el razonamiento inclusivo, donde cada caso aporta a la comprensión del fenómeno de anuncios en establecimientos comerciales que tejen certezas en tiempos de incertidumbre porque las situaciones vivenciada no se apilan, sino que construyen redes de representaciones cognitivas transformadas en herramientas de interacción.

\section{Hasta que nos mate}

IMAGEN 6. HASTA QUE NOS MATE

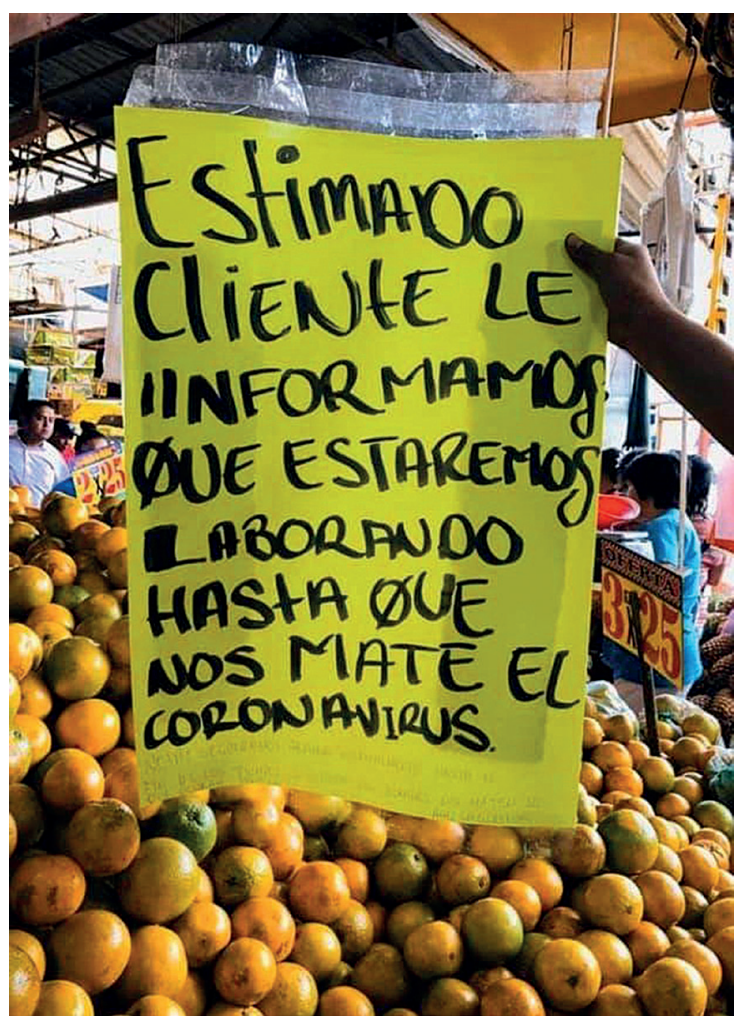

CRÉDITO: CARTULINAS

FLUORESCENTES, 2020. 
TAB LA 5. HASTA QUE NOS MATE

\begin{tabular}{|c|c|c|c|c|c|}
\hline COGNITIVO & LINGUÍSTICO & EPISTEMOLÓGICO & SEMIÓTICO & $\begin{array}{l}\text { ANTROPOLÓGICO } \\
\text { CULTURAL }\end{array}$ & $\begin{array}{l}\text { CIENTÍFICO } \\
\text { PROFESIONAL }\end{array}$ \\
\hline $\begin{array}{l}\text { Informar al "otro" } \\
\text { como parte del } \\
\text { ciclo comercial. } \\
\text { Concepción de } \\
\text { tiempo: hasta. } \\
\text { Nos mate: } \\
\text { agente externo } \\
\text { imposible de } \\
\text { matar. }\end{array}$ & $\begin{array}{l}\text { Redacción de } \\
\text { "usted": respeto y } \\
\text { muestra de verdad. } \\
\text { Texto en plural. } \\
\text { Estaremos: } \\
\text { indicativo, presente. } \\
\text { Laborando: } \\
\text { trabajando para el } \\
\text { "otro". } \\
\text { Coronavirus y no } \\
\text { CovID-19. }\end{array}$ & $\begin{array}{l}\text { Causa efecto de } \\
\text { mantenerse en el } \\
\text { trabajo y fuera de } \\
\text { casa. } \\
\text { Afirmación } \\
\text { categórica del } \\
\text { compromiso } \\
\text { adquirido. } \\
\text { Muerte: concepto } \\
\text { de término de } \\
\text { tiempo. }\end{array}$ & $\begin{array}{l}\text { Anuncio "fuerte } \\
\text { y claro" en el } \\
\text { escenario de un } \\
\text { mercado. } \\
\text { Brazo de color de } \\
\text { piel morena. } \\
\text { Muestra y } \\
\text { demuestra un } \\
\text { comportamiento. } \\
\text { Escrito a mano. } \\
\text { Tamaño de letra } \\
\text { no corresponde } \\
\text { precisamente a la } \\
\text { importancia, sino } \\
\text { al espacio de la } \\
\text { cartulina. }\end{array}$ & $\begin{array}{l}\text { Estimado cliente: } \\
\text { empatía y respeto. } \\
\text { Exponerse a la } \\
\text { muerte. } \\
\text { Juntos ante el } \\
\text { coronavirus. } \\
\text { Tribu que se } \\
\text { concentra frente al } \\
\text { enemigo. } \\
\text { Mercado como } \\
\text { espacio de } \\
\text { convergencia de } \\
\text { tribus e intercambio } \\
\text { de bienes. } \\
\text { Muerte } \\
\text { representada por el } \\
\text { coronavirus. }\end{array}$ & $\begin{array}{l}\text { Consecuencias } \\
\text { de mantener el } \\
\text { servicio como } \\
\text { profesionales. }\end{array}$ \\
\hline
\end{tabular}

FUENTE: ELABORACIÓN PROPIA.

El 11 de febrero del 2020, la Organización Mundial de Salud determinó el nombre de covid-19 (Redacción BBC - Mundo, 2020); sin embargo, los medios de comunicación tradicionales y digitales incluyendo las redes sociodigitales difundieron nombres del virus conforme transcurría el tiempo y los grupos sociales aprendieron y otorgaron significados apolíticos y sentido del humor.

Una de las contradicciones que enfrenta la especie humana es resguardarse para sobrevivir o salir y exponerse a la muerte, pero entre un punto y otro están los requerimientos del capitalismo transformado del siglo XXI, donde para vivir es necesario salir de espacios seguros para tener dinero y adquirir productos indispensables. Una compleja relación causa-efecto.

Las tribus han aprendido a lo largo de los siglos que es más probable sobrevivir juntos y también es la mejor forma de enfrentar al enemigo, a la muerte porque son los "otros" quienes dan sentido a la vida. Los vendedores del puesto 
del mercado han tomado la decisión de enfrentar la muerte a cambio de trabajar y tener ingresos; y ante este peligro es indispensable que los clientes conozcan su decisión para mantener la relación de sobrevivencia entre ambos grupos: vendedor y cliente.

\section{ANÁLISIS Y DISCUSIóN}

Con base en el análisis de los letreros de comercios en tiempos de la pandemia, se tiene un punto de partida para comprender e interpretar procesos de comunicación y acuerdos en el "aquí y ahora" en contextos que potencian la solidaridad, acción, sentido de pertenencia e identidades, así como de la mercadotecnia.

El análisis de discurso de letreros está ubicado entre las etapas 3 de ajuste y el establecimiento de nuevas rutinas, y la etapa 4 de aclimatación a las restricciones y nuevas rutinas y bajo la preocupación sobre la violencia en el país. En este marco, se presentaron evidencias de construcciones discursivas dirigidas al cliente y la familia como tribu con propósitos de comunicación diversos, desde la llamada de atención al cliente por verse expuesto al peligro hasta la decisión de aceptar la muerte por la covid-19. La construcción discursiva se apoya en elementos semióticos que facilitarían la comprensión por parte del cliente desde su cotidianeidad, rebasando el propósito comercial de un anuncio en un local o espacio vinculado con el intercambio de bienes y servicios.

Las representaciones cognitivas de enfermedad, distancia, pareja, un adiós, salud, familia, tribu, entre otras, se insertan en el contexto Covid-19, tienen como propósito la sobrevivencia y salud física y anímica incluyendo la económica, de uno y de todos, donde personas y organizaciones aprenden vivencias, cambian pautas de comportamiento y mediaciones simbólicas. Por supuesto, aún no puede afirmarse que los cambios son transformaciones que pasen de acciones a hábitos y de ahí a costumbres que modifiquen sustancialmente la visión de mundo, pensando en no contaminar tanto al planeta y como sistemas al reorientar la convivencia cara a cara y mediada por la tecnología.

La posibilidad de ser sensible ante la situación de nosotros y de los otros tiene la alternativa de diseñar en interacción física y digital, un compromiso más duradero porque definitivamente en estos meses se tienen ejemplos de las acciones más amorosas y crueles de la humanidad (Sagan, 1986). 


\section{CONCLUSIONES}

El análisis de un suceso comunicativo debe realizarse entre alejamientos y acercamientos, entrelazando las dimensiones y elementos como se propuso en este artículo para tener una imagen de la realidad lo más objetiva posible, es decir, lo más cercana a la realidad misma; lo que permite comprender cómo acciones cotidianas trascienden un pragmatismo y construyen sentido de vida y esperanza aun en ambientes tan amenazantes como la pandemia de Covid-19.

Otras investigaciones que pueden realizarse, considerando los resultados de este análisis son, por ejemplo: insertar los anuncios en contextos más amplios que analicen el alcance de los textos como construcciones de imágenes de la realidad en el marco de la mercadotecnia y recolectando datos de interpretaciones de vendedores y clientes para comprender los letreros no solo del objeto mismo de comunicación sino también de los actores, contextos, visiones de mundo y sistemas involucrados.

Las investigaciones pueden contemplar los siguientes elementos desde el razonamiento inclusivo.

\section{FIGURA 6. ELEMENTOS POR ANALIZAR EN UN ESCENARIO}

\section{MÁS AMPLIO DE LA INTERACCIÓN COMUNICATIVA}

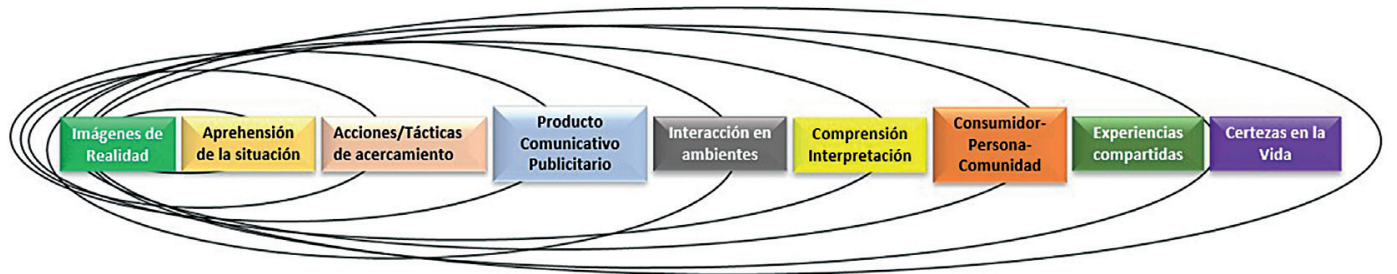

FUENTE: ELABORACIÓN PROPIA.

Es indispensable analizar, comprender y como desde la vida cotidiana los anuncios en locales comerciales pueden generar aprendizajes que contribuyan a una sobrevivencia de la especie humana; esa es la tarea pendiente. 


\section{RE FERENCIAS}

Campos, M. A. (2005). Construcción de conocimiento. Universidad Nacional Autónoma de México.

Canirac. (2020,13 de mayo). Protocolo de prevención CoVID-19: Mesa segura. https://canirac.org.mx/images/notas/files/Protocolo\%20Reapertura\%20-\%20 Mesa\%20Segura_compressed.pdf

Cartulinas Flourescentes. (2020,3 de junio). Anuncios flourescentes. https://www.instagram.com/cartulinasfluorescentes/?utm_source=ig_embed

Lego, E. (2020, 23 de marzo). Trabajo bajo protesta: taquilleras. https://twitter.com/enriquelego/status/1242124561317089280/photo/1

CEHE. (2019). Qué es hostelería de España. https://www.cehe.es/que-es-hosteleria-espana. html

CEPAL. (2020,3 de abril). América Latina y el Caribe ante la pandemia del CoVID 19. Efectos económicos y sociales. https://repositorio.cepal.org/bitstream/handle/11362/ 45337/4/S2000264_es.pdf

Concanaco. (2020,11 de mayo). Mitienda segura. https://www.concanaco.com.mx/mi-tienda-segura/

Coneval. (2020). La política social en el contexto de la pandemia por el virus SARS-CoV-2 (COVID-19) en México. https://www.coneval.org.mx/Evaluacion/IEPSM/Documents/ Politica_Social_COVID-19.pdf

America-Retail. (2019, 6 de junio). México: Industria restaurantera impulsa economía mexicana. https://www.america-retail.com/mexico/mexico-industria-restauranteraimpulsa-economia-mexicana/

AMR. (2020). \#SirviendoaMéxico. http://www.amr.org.mx/noticias.phtml?id=3447\&categoria $=$ NOTICIAS

Ansons, T. M. (2020, abril) (IPSOS, ed.) https://www.ipsos.com/sites/default/files/ct/publication/documents/2020-04/brand-rituals-low-touch-world_web.pdf

Arévalo, R., \& Rebeil, M. A. (2016). Presencia, interacción y responsabilidad social organizacional en las redes sociales digitales de organizaciones privadas en Iberoamércia. En R. Arévalo, \& M. A. Rebeil, Responsabilidad social en la comunicación digital organizacional. Tirant Lo Blanch.

Augé, M. (1992). Los No lugares. Espacios del anonimato. Una antropología de la sobremodernidad. Gedisa.

Bacquerie, J. (2020). Animal MX. https://animal.mx/

Berger, P., \& Luckmann, T. (1966). La construcción social de la realidad. Amorrortu.

Deloitte. (2020). Webcast de la Industria Restaurantera. https://canirac.org.mx/images/ notas/files/Deloitte\%20Webcast_compressed.pdf 
De Certeau, M. L. (1999). La invención de lo cotidiano 2. Habutar, cocinar (1a. ed.). Universidad Iberoamericana, Instituto Tecnológico y de Estudios Superiores de Occidente.

Excelsior. (2020, 6 de abril). ¿Qué hay detrás y qué sigue del movimiento "Aquí nadie truena"? https://www.youtube.com/watch?time_continue=8\&v=5HGS2mbkMpc\&feature =emb_ title\&fbclid=IwAR3NsBFRJLwPXMVCFwJ478SigBYaHtqGhBDGzuPLp6-eg8AJZC6CLdzYRTE

EY. (2020, abril). Impacto de COVID 19 en hostelería en España. https://www.ey.com/Publication/vwLUAssets/ey-bain-company-impacto-de-covid-19-en-hosteleria-en-espana/\$FILE/ey-bain-company-impacto-de-covid-19-en-hosteleria-en-espana.pdf

https://www.ey.com/Publication/vwLUAssets/ey-bain-company-impacto-de-covid19-en-hosteleria-en-espana/\$FILE/ey-bain-company-impacto-de-covid-19-en-hosteleria-en-espana.pdf

Flores, S. (2020). Letras. https://www.letras.com/chava-flores/1063177/

Fernández, F. (2020). Información y opiniones preparadas por CANIRAC. (Deloitte, entrevistador).

Glasersfeld, E. v. (2007). Key Works in Radical Constructivism. A W Rotterdam. SensePublishers.

Google LLC. (2020). Google COVID-19 Community Mobility Reports. https://www.google. com/: https://www.google.com/covid19/mobility/

Gourmet de México. (2020,10 de enero). ¿Hay estrellas Michelin en México? https://gourmetdemexico.com.mx/comida-y-cultura/hay-estrellas-michelin-en-mexico/

Habermas, J. (1999). Teoría de la acción comunicativa II. Taurus.

Hurtado, D. \& Aguirre, G. (2017). La colonia La Condesa en Ciudad de México: Conceptos y productores de lugar. Bitácora urbano territorial, 27(3).

INEGI. (2017). Características de los hogares.

INEGI. (2019, 31 de julio). Resultados del ENIGH 2019. https://www.inegi.org.mx/contenidos/saladeprensa/boletines/2019/EstSociodemo/enigh2019_07.pdf

Instituto de Investigaciones Sociales. (2018, 16 de agosto). Narrativas de Categorías Sociales. México: Instituto de Investigaciones Sociales. https://es.slideshare.net/IIeXLatam/iiexlatam-2018-heriberto-lpez

IPSOS Public Affairs. (2020, abril). What worries the world? https://www.ipsos.com/sites/ default/files/ct/news/documents/2020-04/whatworriesworld_april2020_global.pdf

IPSOS. (2020, 31 de enero). The IPSOS reputation council. https://www.ipsos.com/sites/ default/files/ct/publication/documents/2020-04/the-ipsos-reputation-council-report-april-2020_1.pdf

Iturriaga, J. N. (2018). Biodiversidad y diversidad cultural de México: una cocina históricamente nutritiva y sostenible. En U. México, El Origen y la evolución de la producción de alimentos y su impacto en los patrones de consumo (págs. 173-177). UNESCO México. 
Kotler, P. (2018). The Future of Marketing: An Interview with Philip Kotler, the "Father of Modern Marketing. (S. Shaw, entrevistador).

Kotler, P. (2020, 4 de juio). The Saratosta Institute.https://sarasotainstitute.global/the-consumer-in-the-age-of-coronavirus/

KPMG. (2019, enero). La gastronomía en la economía española. https://assets.kpmg/content $/ \mathrm{dam} / \mathrm{kpmg} / \mathrm{es} / \mathrm{pdf} / 2019 / 01 /$ gastronomia-en-economia-espanola.pdf

KPMG. (2018, septiembre). Anuario de la restauración organizada en España. https://assets.kpmg/content/dam/kpmg/es/pdf/2018/09/anuario-restauracion-organizada-espana.pdf

Makro. (2020, 1 de abril). Impacto del COVID-19 en el sector de la hostelería. https://www. unopuntosiete.es/impacto $\% 20$ coronavirus $\% 20$ en $\% 20$ la $\% 20$ hosteleria.pdf

Marín, A. (2020, 12 de abril). "El 20 por ciento de los restaurantes van a desaparecer. https://elpais.com/elpais/2020/04/11/icon/1586602600_831005.html

Mesa Editorial. (2020, 28 de abril). De la Riva lanza Zona de Reconexión. Merca 2.0. https://www.merca20.com/de-la-riva-lanza-zona-de-reconexion/

Moles, A. (1995). Las ciencias de la impreciso. Miguel Ángel Porrúa, Universidad Autónoma Metropolitana Azcapotzalco.

Morris, C. W. (1946). Signs, Language and Behavior. Prentice Hall.

Nieto, C. (1997). La conciencia lingüística de la filosofía. Ensayo de una crítica de la razón lingüística. Ensayo de una critica de la razón lingüística. Trotta, Fundación Marcelino Botín.

Nosnik, A. (2001). Comunicadores y Organizadores. Planeación y gestión efectiva de su desempeño.

Nosnik, A. (2012). Teoría de la Comunicación Productiva. HomosSapiens.

oMs. (2020). Cómo se transmite la COVID-19. https://www.who.int/es/emergencies/diseases/novel-coronavirus-2019/coronavirus-disease-answers?query=formas $+\mathrm{de}+$ contagio+del+covid19

Ordine, N. (2020, 11 de abril). Edgar Morin: "Vivimos en un mercado planetario que no ha sabido suscitar fraternidad entre los pueblos". El País.

Público, d. (2020, 1 de junio). cartulinasfluorescentes. https://www.instagram.com/p/ CBZWgkZjSAr/

Piaget, J. (1975). Introducción a la epistemología genética. Paidós.

Postman, N. (1991). Divertirse hasta morir. Ediciones de la Tempestad e Ideas.

Redacción. (2020,17 de junio). “De corazón, muchas gracias”, restaurante cierra y así agradece a sus clientes. Excelsior.

Redacción BBC-Mundo. (2020,16 de marzo). News Mundo. https://www.bbc.com/mundo/ noticias-51912089

Rivera, E. (2010). La construcción del problema de investigación en estudiantes de Ciencias de la Comunicación [tesis de doctorado, Universidad Nacional Autónoma de México]. 
Rivera, E. (2019). Transformación del Consumidor: Percepción, autopercepción y microsegmentación; hacia una herramienta de tipificación en marketing y publicidad. 1er Encuentro Nacional de la Red Iberoamericana de Investigadores en Publicidad "Repensar la publicidad y la mercadotecnia: nuevos modelos, nuevos lenguajes". Universidad Anáhuac México.

Scruton, R. (2010). Usos del pesimismo. El peligro de la falsa esperanza. Ariel.

Sánchez de la Nieta, M., \& Fuente, C. (2020). Periodismo vs. desinformación: la función social del periodista profesional en la era de las fake news y la posverdad. Sintaxis, $1(4), 1-18$.

Sagan, C. (1986). Contacto. Plaza \& Janés.

Secretaría de Turismo. (2018). Gastronomía, pilar del patrimonio cultural y la economía mexicana:Sectur.https://www.gob.mx/sectur/prensa/gastronomia-pilar-del-patrimonio-cultural-y-la-economia-mexicana-sectur\#: : text=La\%20gastronom\%C3\%ADa\%20 es\%20una \%20expresi\%C3\%B3n,la\%20Rep\%C3\%BAblica\%2C\%20Salvador\%20S\%C3\%A1nchez\%20Estrada

Shannon, C. E., \& Weaver, W. (1948). The Mathematical Theory of Communication. University of illinois Press.

Signorelli, A. (1999). Antropología urbana. Anthropos, Universidad Autónoma Metropolitana Iztapalapa.

Simetría. (2020, 6 de mayo). El coronavirus y la brecha digital. Animal Político.

The Worlds 50 best. (2020). The World's 50 Best Restaurants. https://www.theworlds50best.com/list/1-50

UNESCO. (2010). La cocina tradicional mexicana, cultura comunitaria, ancestral y viva - El paradigma de Michoacán. https://ich.unesco.org/es/RL/la-cocina-tradicional-mexicana-cultura-comunitaria-ancestral-y-viva-el-paradigma-de-michoacan-00400

Velásquez, A. R. (2018). De los mass media a los medios sociales: reflexiones sobre la nueva ecología de los medios. Revista Latina de Comunicación Social, (73), 583-594.

Watzlawick, P., Bavelas, J. B., \& Jackson, D. D. (1991). Teoría de la Comunicación Humana. Herder.

Woldenberg, J. (2020, 21 de abril). Chava Flores: la esquina de mi barrio. El Universal. 